Research on Language and Social Interaction, 35(3), 311-336

Copyright (C) 2002, Lawrence Erlbaum Associates, Inc.

\title{
Talking With Your Mouth Full: Gustatory Mmms and the Embodiment of Pleasure
}

\author{
Sally Wiggins \\ Department of Social Sciences \\ Loughborough University
}

This article examines the expression of gustatory pleasure as an interactional and discursive construction. Psychological studies of food and eating typically focus on the individual consumer, with bodily experiences conceptualized as internal and private events. It is argued that this approach underestimates the role of discourse and the interactional nature of food consumption. The expression of pleasure is examined here as a constructed and evaluative activity, using conversational examples from family and adult group mealtimes. The "gustatory $\mathrm{mmm}$ " expression is used as a focus for this analysis. Intonation and sequential features of $\mathrm{mmm}$ are seen as essential to the construction of pleasure as an immediate and spontaneous, but descriptively vague experience. The gustatory $\mathrm{mmm}$ also expresses a particularly embodied sense of pleasure. This study therefore contributes to research on 3 levels. First, it extends work on eating practices to incorporate the interactional, conversational domain. Second, it engages with the debate surrounding embodiment and discursive psychology, and extends work in the latter domain to more naturalistic materials. Third, it contributes to the growing body of conversation analytic work on $\mathrm{mmms}$ and response tokens.

I would like to thank Charles Antaki, Jonathan Potter, Karen Tracy, and two anonymous reviewers for their particularly helpful comments on earlier versions of this article. I am also indebted to Malcolm Young for providing the impetus for this article.

Correspondence concerning this article should be sent to Sally Wiggins, Department of Social Sciences, Loughborough University, Brockington Building, Loughborough, Leicestershire, UK LE11 3TU. E-mail: s.k.wiggins@lboro.ac.uk. 
Eating can involve, among other things, pleasurable tastes and flavors. Within psychological research, gustatory pleasure is largely conceptualized as a physical experience - as something that can be directly accessed via participant responses (e.g., Cardello, Schutz, Snow, \& Lesher, 2000; Frijters, 1987; Grogan, Bell, \& Conner, 1997; Hetherington, Pirie, \& Nabb, 1998). Despite this, there has been relatively little research on the pleasurable or enjoyable aspects of food (Dubé \& Cantin, 2000); the overwhelming emphasis has been on research examining the negative aspects of diet, eating disorders, and cultural norms (e.g., Bordo, 1997; Germov \& Williams, 1996; Hill \& Franklin, 1998). In particular, there has been little concern with how "pleasure" can be defined, and how it is constructed as an individual, embodied experience. This article examines how pleasure is expressed and oriented to in conversation, and the implications of this for discursive theories and notions of embodiment. The "gustatory $m m m$ " has been chosen as a topic for analysis as it appears to be central to the expression of pleasure during eating.

The focus on the individual consumer is characteristic of psychological research on food, in which eating is regarded first and foremost as a physiological and cognitive activity (e.g., Conner, Martin, Silverdale, \& Grogan, 1996; Herman \& Polivy, 1980; Wardle, 1988). The social and interactional nature of food consumption is sectioned off as an independent variable, made up from either the consumer's perception of social norms or the mere presence of other consumers. Hence it is typically regarded as an influence on, rather than being central to, food choice and eating behavior. For example, Conner, Povey, Sparks, James, and Shepherd (1998) made a distinction among factors relating to the food, the environment (social and cultural), and the individual (psychological and physiological). Gustatory pleasure would be included in this latter category, and social and cultural factors are considered here as not only external to the individual, but also as separable and independent influences.

This article argues that the social nature of eating - interacting with friends over dinner and offering and accepting food, for example - is more than just another factor to be considered in the analysis; rather, it is fundamental and inseparable. Likewise, pleasure can be regarded as a social phenomenon that is bound up with interaction and communication. Food is always already social: It becomes so from the moment we orient to it as food. For example, we relate to others through acts of giving, sharing, and withholding food, and our eating practices are embedded within daily (e.g., dinner) and annual (e.g., Christmas dinner) routines (DeVault, 1991; 
Visser, 1986, 1991). In this way, eating is bound up with cultural, historical, and social practices (e.g., Beardsworth \& Keil, 1997; Lupton, 1996; Mead, 1997; Meigs, 1997). An interactional approach to eating attends to these practices (Ochs, Pontecorvo, \& Fasulo, 1996; Pontecorvo \& Fasulo, 1999; Wiggins, Potter, \& Wildsmith, 2001) and is used in this study to examine how the pleasure of eating is embedded in discourse.

To see how an interactional approach might be useful, consider how current methods are used to measure gustatory pleasure. For instance, participants in psychological studies may be asked to rate the pleasantness of a food on a numbered scale or questionnaire (e.g., Geiselman et al., 1998). In this way, pleasure is represented as something quantifiable. Hedonistic scales present levels of gustatory pleasure that can be compared as individual responses to different foods. In contrast, the approach taken here argues that making a distinction between private experience and public expression is problematic. Pleasure may involve elaborate utterances or facial movements. It is also organized at an interactional level. For example, speakers may display a pleasant taste experience when they commence eating, but this is not repeated at every mouthful. Similarly, speakers are less likely to express such a reaction when eating alone. One such expression, which will be used in this analysis, is the gustatory $\mathrm{mmm}$.

The main aims of this study are to

1. Examine the organization of the gustatory $\mathrm{mmm}$ as it occurs in interaction. I demonstrate how the expression is recipient designed and organized sequentially in talk.

2. Consider the involvement of the expression in conversational activities. How might it be oriented to action? How does it contribute to evaluations of food and drink?

3. Illustrate how an examination of expressed gustatory pleasure helps us understand the way embodiment enters into interaction. How is pleasure constructed as an individual and private bodily experience?

\section{EMBODYING TALK}

This study uses the approaches of discursive psychology (DP; Edwards, 1997; Edwards \& Potter, 1992; Potter, 1997) and conversation analysis (CA; e.g., Atkinson \& Heritage, 1984; Hutchby \& Wooffitt, $1998)$ to examine gustatory pleasure in interaction. DP focuses on the ac- 
tion orientation of discourse and on how constructions are built up in talk. For example, having an attitude is regarded as something that is achieved through talk - a practice, rather than an internal, cognitive state (Burningham, 1995; Potter, 1998; Potter \& Wetherell, 1987; Puchta \& Potter, 1999; Verkuyten, 1998). CA focuses on turn organization, highlighting intonation, and sequential features of talk. Combining these two approaches allows us to analyze how issues that are usually conceived to be psychological in nature - such as pleasure, eating, and embodiment - intersect with the organization of everyday interaction.

One of the aims of this article is to illustrate how embodied practices are constructed in sequences of conversation (see also Billig, 1999; Edwards, 1997, 1999; Wittgenstein, 1953, on emotion as an embodied construction). However, recent debates within sociology generally, and discursive psychology in particular, have raised the issue of embodiment as a potential problem for analyses that focus on talk (Burr, 1995, 1999; Gergen, 1999; Parker, 1998; Willig, 2000). It has been argued that discursive research does not take embodiment seriously, and that what have been defined as extra discursive features are disregarded or overlooked by such analyses (Burkitt, 1999; Burr, 1999; Crossley, 2001; Kempen, 1998; Sampson, 1998). My concern here is to demonstrate that this need not be the case if we look at how embodiment is constructed in specific examples of interaction. More important, rather than set up a body-discourse dualism, it may be more revealing to examine how the body is constructed as being extra discursive in participants' talk. In other words, how do references to bodily states, tastes, and eating construct the body as something outside of, or distinct from, discourse. It is not that we need somehow to gain access to underlying bodily states, but that the concepts of "body" and "discourse" may be seen themselves as interrelated and interactional constructions.

\section{The Conversational $\mathrm{Mmm}$}

The $\mathrm{mmm}$ expression has already received analytical attention within CA research. Different forms of the expression have been classified according to organizational features and uses of the term (e.g., Czyzewski, 1995; Gardner, 1997, 2001; Schegloff, 1982). This work illustrates the necessity to examine intonation, because this can determine what type of $\mathrm{mmm}$ is being expressed. For example, a "repair initiator $\mathrm{mmm}$ " character- 
istically has a rising intonation, and is used to mark a possible error in a previous turn (Gardner, 2001). The sequential features of $\mathrm{mmms}$ are also important in determining their function in talk, such as whether the $\mathrm{mmm}$ occurs in overlap or in response to a previous turn (e.g., Jefferson, 1984; Koole, 1998; Schegloff, 1982). Among these various types, a "degustatory mmm" (Gardner, 1997, p. 150) has been identified as primarily associated with eating and drinking practices. The gustatory $\mathrm{mmm}$ referred to in this study bears a strong resemblance to Gardner's term, although here the expression is typically characterized by an emphasized or exaggerated expression, with a rising or falling intonation, or both.

I define the gustatory $\mathrm{mmm}$ as (a) accompanying eating or talk about food and drink (or both) and (b) hearably evaluative in a positive direction. It is examined here in terms of its involvement in the construction of gustatory pleasure. Intonational variations between gustatory and nongustatory $\mathrm{mmms}$ are shown to highlight the rhetorical flexibility and constructive nature of these expressions. The sequential position of the gustatory $\mathrm{mmm}$ is also a prime concern here. For example, how does the placement of the expression display or construct a bodily pleasure, and how do other speakers orient to this? The focus in this article is therefore on the organization of the gustatory $\mathrm{mmm}$ in talk, and its involvement in constructing the pleasures of eating.

\section{CAPTURING THE GUSTATORY MMM}

\section{The Mealtime Conversations}

The data used in this study were taken from tape-recorded family mealtimes. Family groups were used for both practical and analytical reasons. Pilot research suggested that couples with children were more likely to eat together regularly than were other adult groups. Ten families were recruited on this basis to self-record their meals (the extracts here use data from 3 families). Each family consisted of 2 parents and at least 1 child between the ages of 4 and 23 years. In addition to this data, a nonfamily group meal consisting of 2 adult couples (ages 23-27 years) was included to supplement the data corpus and to provide further examples of the gustatory $\mathrm{mmm}$. The virtue of including these data is to be able to check that 
analytic conclusions are not restricted to family conversations. Participants were selected from different locations around England, providing a limited geographical spread. The aim of the research is to inform our understanding of eating practices, which are potentially culturally specific. Thus, it is not appropriate to generalize the findings, or attempt to provide a universal account of gustatory pleasure.

The researcher supplied recording equipment and the families were asked to self-record their meals as regularly as possible within household routines. The equipment was left with each family for approximately 3 months - the aim being to build a corpus of naturalistic conversational material. In this way, instances of the gustatory $\mathrm{mmm}$ could be seen as they arose in daily interaction. The recorded conversations were transcribed using standard Jefferson notation. Repeated listenings to and reading of the data highlighted the occurrence of different types of $\mathrm{mmm}$ expression. The analysis then focused on one of these (the gustatory $\mathrm{mmm}$ ) as a particular interactional expression associated with eating or talking about food.

\section{Gustatory Mmms and Intonation}

The gustatory $\mathrm{mmm}$ can be distinguished from other $\mathrm{mmm}$ s by the extended and emphasized form, occasional rising or falling intonation, and sequential placement within the context of eating. It is also a relatively infrequent term in comparison with other forms of the expression, even during mealtime conversation (Gardner, 1997, 2001). These features allow us to distinguish the gustatory $\mathrm{mmm}$ from the variety of other $\mathrm{mmms}$ that have been highlighted in previous research (e.g., Czyzewski, 1995; Gardner, 1997; Jefferson, 1984; Koole, 1998; Schegloff, 1982).

To give an example of what is meant by a gustatory $\mathrm{mmm}$, the following extract provides an illustration that includes a particularly graphic sequence of gustatory mmms. The family has just begun to eat their Christmas dinner.

(1) SKW/K1a-M2 (56-69) ${ }^{1}$

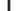

2 Sandra: $\rightarrow \uparrow \underline{\mathrm{mmm}}(0.4) \uparrow \underline{\mathrm{mm}} \downarrow \mathrm{mm} \uparrow \mathrm{m}::$

3 Ian: $\rightarrow \uparrow \mathrm{mm} \downarrow \mathrm{m}-\mathrm{m} \uparrow \mathrm{mmm}::: \mathrm{m} \uparrow \mathrm{mmmm}:$

4 Sandra: $\rightarrow$

5 mm $\downarrow \mathrm{m}[\underline{\mathrm{m}} \underline{\underline{\mathrm{mmmm}}::: \mathrm{m} \uparrow \mathrm{mmmm}:}$ 


\begin{tabular}{|c|c|}
\hline 6 Sandra: & $(($ clears throat $))$ just cope with this \\
\hline & every $\uparrow$ da:y \\
\hline & $(1.4)$ \\
\hline
\end{tabular}

Although this may be a rather exaggerated example, it displays the flexibility of the expression, in that both rising and falling intonation are used to great effect. Note how Sandra's turn is almost mirrored by Ian's, and is overlapped by further elaboration. This collaboration of similar sounds suggests that the expression is unproblematic here; no explanation is required before Ian joins in with the display. Sandra refers back to the food ("just cope with this every day," line 6), but there is no questioning of the $\mathrm{mmm}$ expression itself.

A different type of $\mathrm{mmm}$ can be used here to offer a contrast and to highlight the importance of subtle changes in intonation. The following extract illustrates a "continuer $\mathrm{mm}$ " (line 3 ), characterized by a rising intonation (Gardner, 1997).

(2) SKW/D3a-M5 (211-216)

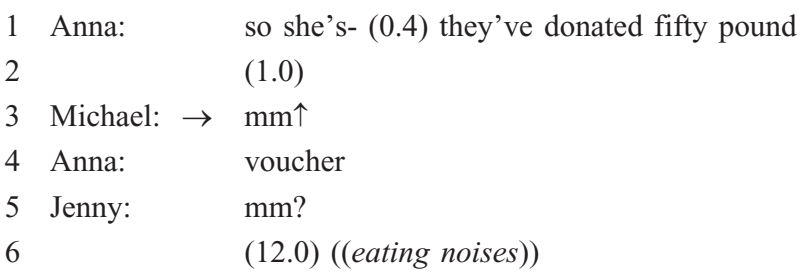

The $m m \mathrm{~s}$ in this extract are different from the gustatory $m m m$ in that they are primarily associated with the acknowledgment of another speaker, rather than with the food. The intonation is also less pronounced, without any added emphasis. So not only is there a different intonation, there is also a different topic, and focus, of the talk.

At the risk of being overly simplistic, Table 1 provides a summary of distinctions between gustatory and nongustatory $\mathrm{mmm}$ expressions. This was used to aid analysis and identification of the expression, and is provided to clarify the distinction for the reader.

\section{ANALYSIS}

The analysis is divided into three sections. The first examines the status of the gustatory $\mathrm{mmm}$ as an interactional activity. I argue that pleasure is organized sequentially in conversation. The second section highlights 
TABLE 1

Description of Gustatory and Nongustatory Mmms

\begin{tabular}{|c|c|c|c|}
\hline \multirow{2}{*}{$\begin{array}{l}\text { Expression } \\
\text { Type }\end{array}$} & \multicolumn{3}{|c|}{ Common Features of the Expression } \\
\hline & Sequential Organization & Topic & Intonation \\
\hline $\begin{array}{c}\text { Gustatory } \\
m m m s\end{array}$ & $\begin{array}{l}\text { Follows the presence of } \\
\text { eating, or talk about } \\
\text { food and drink }\end{array}$ & $\begin{array}{l}\text { Associated with food, } \\
\text { drink, or eating } \\
\text { practices }^{\text {a }}\end{array}$ & $\begin{array}{l}\text { Emphasis; exaggerated } \\
\text { rising or lowering } \\
\text { intonation; can be } \\
\text { extended or repeated }\end{array}$ \\
\hline $\begin{array}{l}\text { Nongustatory } \\
m m s\end{array}$ & $\begin{array}{l}\text { Follows a wide range of } \\
\text { activities }\end{array}$ & Nonspecific to topic & $\begin{array}{l}\text { Various forms, although } \\
\text { often shorter, without } \\
\text { emphasis }\end{array}$ \\
\hline
\end{tabular}

${ }^{a}$ A possible extension of this category could include other bodily sensations associated with pleasure, for example, massage, or sexual experiences. Gardner (2001) briefly alluded to these types of sensation.

evaluative features of the expression and how this is partly achieved through a construction of immediacy, spontaneity, and vagueness. Finally, the construction of gustatory pleasure as an embodied event is considered in the third section.

\section{Bringing Pleasure to the Talk}

A characteristic feature of mealtimes is the intermittent presence of food. As food is brought to the table, eaten, and then cleared away, it moves in and out of relevance for the diners. Within the data corpus, orientation to the food and eating were only occasional activities for the family members; that is, they did not display a taste reaction at each and every mouthful. The nature of these orientations raises questions for the conventional notion of gustatory pleasure as discussed previously. If we regard pleasure in term of how it is expressed in interaction, then we need to take situated conversational practices into consideration (see Sacks, 1992; Sacks, Schegloff, \& Jefferson, 1974).

The interactional features of bodily expressions have been similarly argued in the works on laughter by Gail Jefferson (1985; Jefferson, Sacks, \& Schegloff, 1987; see also Mulkay, 1988). She demonstrated how laughter that seems spontaneous is coordinated with other speakers' actions. Similar to taste sensations, which are generally taken to be outside of conscious control, laughter may perhaps be more structured. As an example of 
this with regard to pleasure, the following extract illustrates how the expression of pleasure may appear to be coordinated with other turns in the conversation (Sacks et al., 1974). In this extract, the family is near the start of their meal, and food is being passed around the table.

(3) SKW/D2b-M4 (132-142)

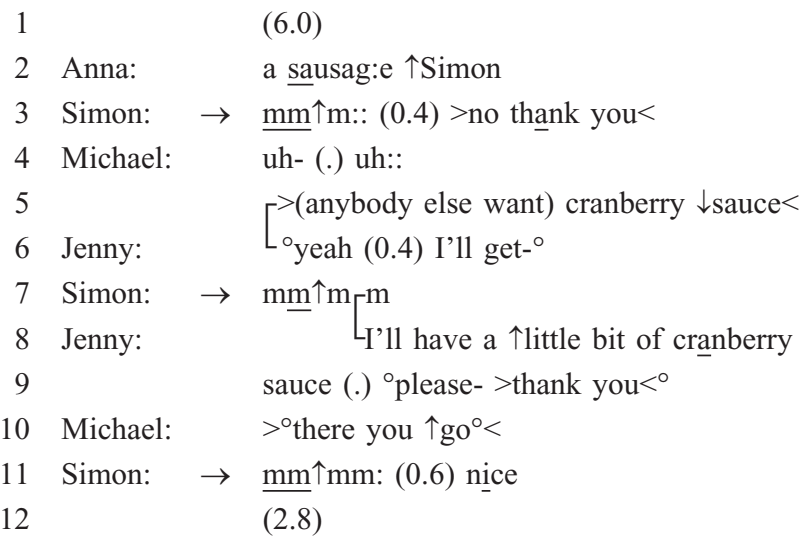

The turns immediately prior to the mmms appear to be, and are treated as, complete utterances; that is, Simon expresses pleasure from the food at transition relevance points (TRPs; Sacks et al., 1974). Such a placement suggests that the $\mathrm{mmm}$ is at least as much an interactional item as an immediate, causal response to inner sensations. Note that it signals not only Simon's orientation to the talk (through its placement at a TRP), but also his inability to contribute more fully to the conversation. For example, his $\mathrm{mmm}$ on line 3 displays to Anna that he is attending to food currently being eaten, given that this is articulated first, and followed by a brief pause. The repeated and emphasized $\mathrm{mmm}$ expressions (lines 7 and 11) continue to demonstrate his engagement with the food. By drawing attention to his consumption in this way, he is also signaling to other speakers that he is unlikely to talk in more depth. This is particularly supported by the speeded up "no thank you" on line 3.

Other speakers may attend to the gustatory $\mathrm{mmm}$ more explicitly. What may seem to be an individual experience of the food-and apparently inaccessible to others - can become a focus for the interaction. In the following extract, Anna reformulates Simon's expressions as an overarching taste preference. At the start of the extract, Anna moves two cats that have been lying on the dining room chairs. 
(4) SKW/D1a-M1 (36-47)

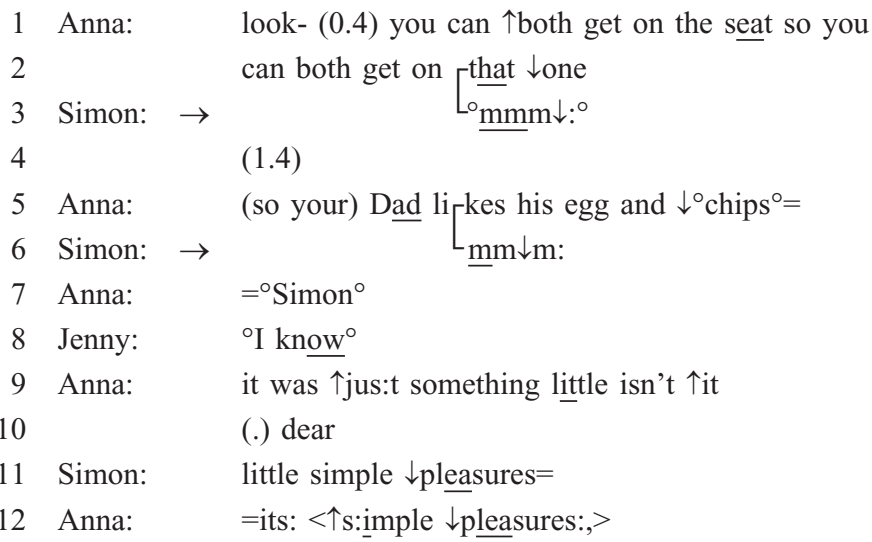

In her analysis of laughter, Jefferson (1985; Jefferson et al., 1987) noted that reports of others' laughter are usually in the form of "he laughed" rather than "he went 'ah heh heh heh" " (Mulkay, 1988, p. 110). Similarly, the $\mathrm{mmm}$ expression is rarely used as part of a verbatim report. In Extract 4, Anna reformulates Simon's mmms as being evidence of his "liking" egg and chips (line 5). The point being made is that Simon's enjoyment is specific to the food, which Anna served, at this meal. Moreover, the later constructions of "simple pleasures" (lines 9-12) suggest that it is the food itself that is the source of the pleasure. Note also how the intonation of these mmms contrasts with that of a continuer $\mathrm{mm}$ (seen in Extract 2) and how the orientations of the other speakers differ. What began as the expression in terms of a personal experience becomes a feature of the food, and a focus for the interaction.

\section{The Mmm-Plus-Evaluation Sequence}

In the data corpus, the gustatory $\mathrm{mmm}$ was at times followed by an explicit evaluative term (e.g., " $m m m$ that's nice"). Table 2 details the number of instances of mmms in relation to evaluative terms, or where they occurred as freestanding expressions.

The freestanding gustatory $\mathrm{mmm}$ was the most common occurrence, often displayed in response to a previous speaker's turn. The $\mathrm{mmm}$-plusevaluative term ${ }^{2}$ sequence was the predominant pattern on those occasions in which a speaker provided an additional expression (take the following example). 
TABLE 2

Frequency of Mmm Forms

\begin{tabular}{lrr}
\hline & \multicolumn{2}{c}{ Instances in the Data Corpus } \\
\cline { 2 - 3 } Sequence of Gustatory Mmms and & \multicolumn{1}{c}{ No. } & $\%$ \\
\hline Evaluative Terms & 147 & 70 \\
Mree-standing mmms & 60 & 28 \\
Evaluative term-pluative term & 5 & 2 \\
Total & 212 & - \\
\hline
\end{tabular}

(5) SKW/D5a-M8 (636-638)

$1 \quad(0.8)$

2 Simon: $\rightarrow$ mm个mm: (0.2) that's $\uparrow$ lovely

$3 \quad(0.6)$

The extended expression of pleasure ("mm个mm," line 2) occurs here prior to the descriptive account ("that's lovely"). Expressing gustatory pleasure in this way suggests a reaction to a bodily sensation followed by a descriptive account. Note also that both the $\mathrm{mmm}$ and the more explicit evaluation are uttered in close proximity within the same turn. This has the effect of tying the expressions together-the $\mathrm{mmm}$ is there seemingly because the food is lovely. Likewise, the loveliness appears to refer specifically to the pleasurable sensations of the food.

A variation on this sequence involves instances in which the explicit evaluative component (e.g., "lovely" or "nice") occurs in the same speaker's next turn later in the conversation. We saw this earlier in Extract 3 with Simon uttering a few mmms before the more explicit term, "nice" (line 10). The following extract shows a similar sequence with two speakers (Lynn and Rick) displaying the $\mathrm{mmm}$-plus-evaluation pattern over a series of turns. Jenny prepared the chocolate pudding that is currently being eaten, and Michael is continuing a previous narrative.

(6) SKW/MG2-20-2-99 (2646-2659)

$\begin{array}{lll}1 & & (0.4) \\ 2 & \text { Lynn: } & \text { this is }(0.2) \text { excellent } \\ 3 & \text { Rick: } \rightarrow & \underline{\operatorname{mm} \uparrow \mathrm{mm}:} \\ 4 & \text { Michael: } & \text { so- }(0.4) \\ 5 & \text { Jenny: } & \end{array}$




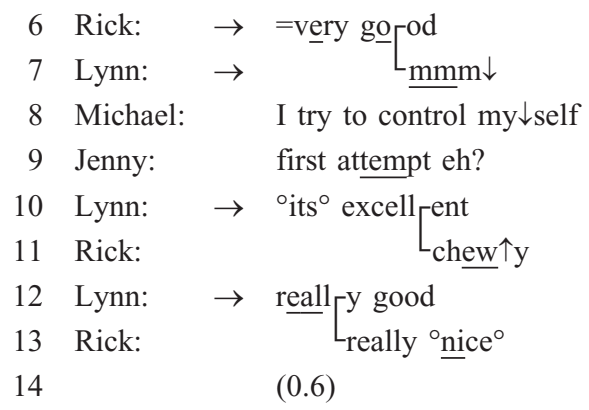

The order of the expressions is important here. After Lynn's initial, "this is excellent" (line 2), both Rick and Lynn express pleasure from eating before evaluating the food more explicitly. It is this prefacing of the more explicit evaluation with the $\mathrm{mmm}$ that adds to the subtlety of its meaning. The different intonation of the mmms also suggests both initial pleasure (rising intonation, line 3 ) and confirming other evaluations (falling intonation, line 7). Note that the gustatory $\mathrm{mmm}$ alone is not treated as an incomplete expression. The separation between the $\mathrm{mmm}$ and the evaluative term, by other speaker turns, suggests that the $\mathrm{mmm}$ itself works (and is oriented to; see lines 3 and 5) as an evaluation. In particular, it displays an evaluation of the food at what is seemingly the most basic, physiological level. Here, we begin to see something of the construction of embodied pleasure. The predominant organization and intonation of the gustatory $\mathrm{mmm}$ highlight three key features of pleasure construction: immediacy, spontaneity, and vagueness. I examine these in turn next.

Immediacy. Having a mouth full of food severely restricts what can be clearly articulated. The $\mathrm{mmm}$ expression is one that can be uttered effectively and, perhaps, politely while eating because it does not require movement of either the tongue or lips. ${ }^{3}$ This makes it a useful resource in mealtime conversation, for one can respond to another speaker almost immediately, even while eating. It is this immediacy that constructs the pleasure of the gustatory $\mathrm{mmm}$ as an evaluation based on what is being experienced physically at that particular moment. The gustatory $\mathrm{mmm}$ seems to capture the sensation as being experienced at that moment. Extract 7 provides an illustration of this. At this point in the meal, the family is near the end of their main course. 
(7) SKW/D3a-M5 (713-720)

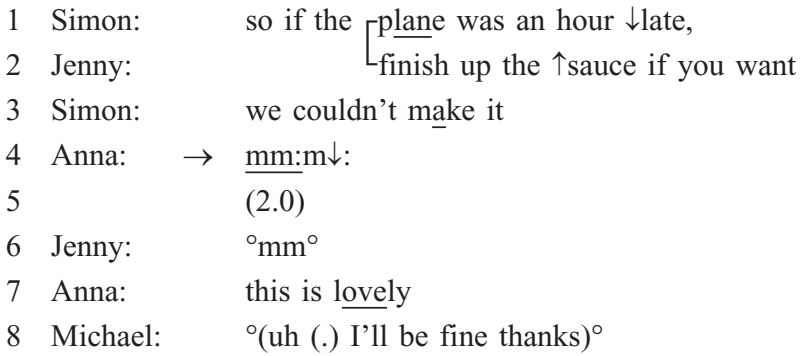

A notable feature of this example is Anna's expression of enjoyment (line 4) soon after an offer of more food is $\operatorname{made}^{4}$ (line 2). In doing so, she displays an orientation to the food as a source of pleasure, while simultaneously acknowledging Jenny's offer. The short delay before she comments more directly ("this is lovely," line 7) serves to emphasize the role of the $\mathrm{mmm}$ as an on-the-spot response. It highlights the immediacy of the first reaction, as being expressed while the food could still be tasted. The evaluation in line 7 then supports this as a verbalized response to the food.

Extract 8 offers a further illustration of the rhetorical force of the gustatory $\mathrm{mmm}$ when it is spoken while eating. Robert is the father of this family; Nicholas, Daisy, and Adam are his children. "Daddy's cheese" has just been offered to the children, who proceed to comment on its smelly qualities. This part of the conversation immediately follows.

(8) SKW/L1a-M3 (993-1001)

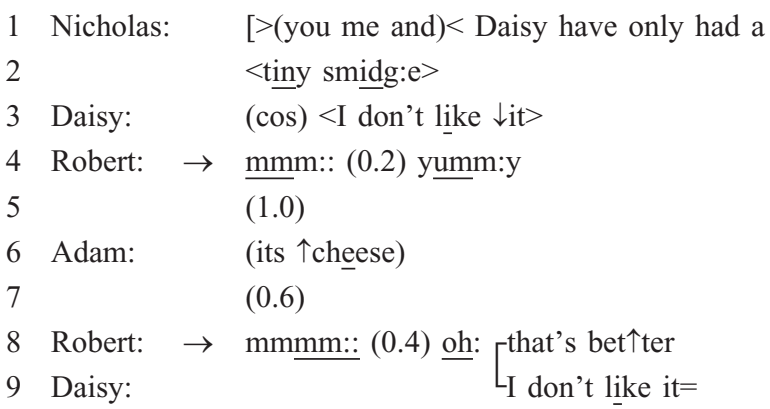

The discussion about who likes, or does not like the food is restricted to the children at this point in the conversation. Robert's contributions make 
no reference to whether he likes the cheese, although this is implied through his expressions of gustatory pleasure (lines 4 and 8). By expressing what may be treated as a reaction to the taste of the food $(\mathrm{mmm})$, he presents an evaluation in terms of the qualities of the cheese itself. This is displayed as a response to the act of eating rather than a preexisting preference for the cheese (see also Wiggins, 2001). Note also that his turns do not directly attend to the other speakers' talk. In this sense, he avoids direct disagreement with the others, but still presents an alternative evaluation.

The immediacy of the gustatory $\mathrm{mmm}$ builds on the notion that this is a bodily sensation. Drawing on the concept of a news receipt (Heritage, 1984), we could refer to the gustatory $\mathrm{mmm}$ as a "sensation receipt," in that it displays an immediate orientation to a taste experience. This is particularly noticeable when a rising intonation occurs (e.g., $\underline{\mathrm{mm} \uparrow \mathrm{m}}$ ). The notion that one can display an evaluation of food through reference to a bodily sensation is of no small consequence. For example, research on attitudes typically rely on rating scales and questionnaires, which are thought to provide access to internal beliefs (e.g., Eagly \& Chaiken, 1993, 1998). Language is used as a tool, as distinct from the attitude or the sensation. Here, the gustatory $\mathrm{mmm}$ is an expression that not only alludes to a bodily sensation, but also evaluates the food simultaneously. These displays of pleasure present the body itself as seeming to inform the assessment. Hence the body, expression, and evaluation are not so easily separated.

Spontaneity. Another feature of the gustatory $\mathrm{mmm}$ is its construction of a spontaneous sensation. Not only can it be produced immediately after (or while) food is eaten, but it can be expressed at various points in the interaction. There is no requirement to preface the expression or announce a topic change (see also Extract 12). Indeed, displaying pleasure from the food when others are engaged in a separate conversation may serve to enhance the authenticity of the expression. Take, for example the next extract (an extension of Extract 1), from a family Christmas dinner. Although this exchange occurs after a brief lapse (4 sec) in the talk, Ian almost immediately follows Sandra's lengthy $\mathrm{mmm}$ expression.

(9) SKW/K1a-M2 (59-72)

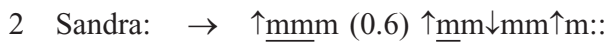

3 Ian: $\rightarrow \uparrow \mathrm{mm} \downarrow \mathrm{m}-\mathrm{m} \uparrow \mathrm{mmm}:::::$

4 Sandra: $\rightarrow \quad[\overline{-\underline{m m m} \downarrow \mathrm{mmm}:::}$ 
5

6 Sandra: $\quad(($ clears throat $))$ just cope with $\uparrow$ this: every da:y

7

8 Sandra:

9 Ian:

10

11 Sandra:

12 Ian:

13 Sandra:

14
(1.6)

${ }^{\circ}$ hhmm hhmm hmmm $^{\circ}$

${ }^{\circ} \mathrm{hmm} \mathrm{hhm}{ }^{\circ}(0.4)$ you mean the

drin(hh)king and the stupidity: heh heh

个no (0.2) the prawn $\uparrow$ cocktail

oh right $=$

$={ }^{\circ}$ hheh $^{\circ}$

(3.0)

It is particularly revealing that despite the collaboration of displays of pleasure, there is some uncertainty over the focus of, or reason for, the display. Whereas Sandra refers to the specific food they are eating (prawn cocktail), Ian formulates the talk in terms of the festive season more generally (the "drinking and the stupidity"). Despite this, the expression was not questioned by any of the other speakers ( 3 children were also present at this meal). The extract also demonstrates a further activity of the gustatory $\mathrm{mmm}$ - that of indicating alignment between speakers (e.g., Heritage, 1984; Nofsinger, 1991). By expressing a similar evaluative turn in overlap, Sandra and Ian appear to be sharing an experience of the food. Note that this is regardless of what they are actually tasting. The point is that it gives the appearance of sharing pleasure. This in itself is a social action.

The $\mathrm{mmm}$-plus-evaluation format was noted earlier as being the predominant pattern in which gustatory $m m m s$ were accompanied by further expressions. The reverse of this pattern (evaluation-plus- $\mathrm{mmm}$ ) was seen to occur in only $5 \%$ of instances in the data. We could therefore note this pattern as being a set of deviant cases, and these confirm the importance of the gustatory $\mathrm{mmm}$ as a spontaneous evaluation. Consider Extract 10: Lynn is a guest at an adult group meal, and has been recounting a description of the food eaten on a previous occasion. Rick is Lynn's partner, Jenny is the hostess.

(10) SKW/MG2-20-2-99 (133-141)

1

2 Lynn:

3 Jenny:

4 Rick:

5 Lynn:
(1.0)

and it was $\underline{\text { rea: }: 1 l y ~}\left[\begin{array}{l}\text { flavorsome } \\ \text { ooh:: }\end{array}\right.$

ye $\left[\frac{\text { ah: }}{\text { it }}\right.$ was $>{ }^{\circ}$ really ${ }^{\circ}$ really $<\operatorname{good}(0.4)$ (its) 


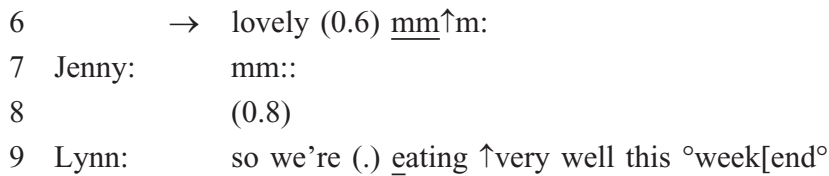

Having already described the food eaten previously in some detail, Lynn sums up at this stage by saying that it was "really flavorsome" (line 2) and "really really good" (line 5). The overemphasis on this account (particularly the use of "really really") highlights the fact that the food at this meal has not nearly been complimented to the same degree. It may appear as if Lynn is not appreciative enough of her hostess's culinary skills. The gustatory $\mathrm{mmm}$ on line 6 thus serves to bring the conversation around to the current food, although it is unclear as to whether the "lovely" refers to this particular meal. Following the evaluative term, the $\mathrm{mmm}$ appears to be more forced or contrived. Note also that it has a rising intonation, suggesting a sensation receipt of the experience, even though Lynn had already begun eating. It is as if she is backtracking so as not to offend her hosts. Indeed, she makes a more elaborate repair on line 9, working to align both meals as occasions during which they have eaten "very well."

The occurrence of the gustatory $\mathrm{mmm}$ within the latter part of a turn thus appears to diminish the authenticity of the speaker's response. Extract 11 is a continuation of Extract 8 and shows how pleasure can be expressed to make a particular point.

(11) SKW/L1a-M3 (999-1005)

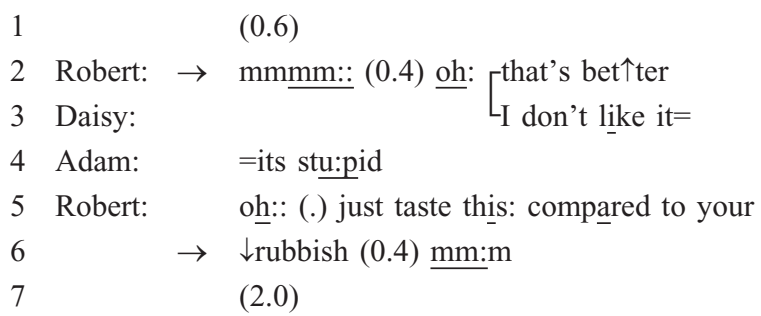

If we first focus on the second $\mathrm{mmm}$ (line 6), it appears as if Robert is exaggerating his displays of pleasure to make a point about the cheese (previously referred to as "Daddy's cheese"). The $m m m$ (line 6) appears to be more contrived than that on line 2 , and note that neither displays a rising or falling intonation. It is less spontaneous, fitting into the sequence of the talk rather than being expressed as a response to a bodily sensation. By 
making direct comparisons to the other, unnamed food- "that's better" (line 2) and "your rubbish" (line 5) - Robert is claiming to own, or have a preference for, the better food. Not only can he say how much he is enjoying the cheese, but he can show it as well.

The sequential organization of the gustatory $\mathrm{mmm}$ is clearly an important feature in the construction of spontaneity. In the $\mathrm{mmm}$-plus-evaluation sequence, the gustatory $\mathrm{mmm}$ was noted to act similar to a sensation receipt. The significance of the $\mathrm{mmm}$ prior to further elaboration becomes apparent when one examines the reverse sequence (evaluation-plus$\mathrm{mmm}$ ). In this case, the $\mathrm{mmm}$ lacks spontaneity and immediacy, given that an evaluation has already been expressed descriptively. Referring to the taste experience directly then seems somehow contrived, as if it was being expressed as empirical support, and not as an experience in itself. It is only when the $\mathrm{mmm}$ appears first does it construct the spontaneity of pleasure as an immediate taste sensation.

Vagueness. The intonational pattern of gustatory $m m m s$ that allows for flexibility also contributes to the ambiguity of the expression. It exudes vagueness with respect to both semantic content and its role in the interaction, because neither is explicitly articulated by the gustatory $\mathrm{mmm}$ alone (cf. Koole, 1998). Although it suggests that there is some associated bodily sensation, it fails to specify exactly what it is about the food that makes it pleasurable. The vagueness of the expression also contributes to its involvement in interactional activities. For example, $\mathrm{mmm}$ can be used not only to avoid specifying taste attributes, but also to avoid attending directly to the conversational topic. Displaying a physical reaction allows a speaker to step out of the interaction to some extent. Referring to the body, or the food, can be treated as a separate part of the interaction. For example, Simon's evaluation of the food in Extract 12 is left unattended by the other speakers. What is notable about this evaluation is that the main topic of conversation is about another, less-appetizing food (uncooked sprouts).

(12) SKW/D5a-M8 (631-638)

\begin{tabular}{|c|c|c|}
\hline 1 & Jane: & fla $\Gamma$ sh: $\downarrow$ boi(h)led \\
\hline 2 & Simon: & $\mathrm{L}_{\text {yeah }}$ \\
\hline 3 & Anna: & $>\underline{\mathrm{mmm}}<$ \\
\hline 4 & & $(0.4)$ \\
\hline 5 & Peter: & they were actually raw: they $<\uparrow$ crunched $>$ in \\
\hline 6 & & your mouth \\
\hline
\end{tabular}




$\begin{array}{rll}7 & & (0.8) \\ 8 & \text { Simon: } \rightarrow & \text { mm: } \downarrow \mathrm{m}(0.2) \text { that's } \uparrow>\text { lovely }< \\ 9 & \text { Anna: } & \text { even Nat }>\text { couldn't eat them }<{ }^{\circ} \text { could } \uparrow \text { she }^{\circ} \\ 10 & & (0.4) \\ 11 & \text { Peter: } & >\text { she was the one }<\text { who } \uparrow \text { cooked them }\end{array}$

It is apparent from the content of the talk here that what Simon refers to as "lovely" is not the same item of food discussed in the surrounding talk. This is evidenced by both the emphasized $\mathrm{mmm}$ (line 8 ) and by the lack of speaker orientation to Simon's turn. The expression of pleasure enables Simon to opt out of the conversation to some extent, as if this were an aside. The $\mathrm{mmm}$ bases the evaluation in immediate, physical experience-and provides the context in which "that's lovely" is to be heard. In other words, it marks this turn as being distinct from the topic under discussion.

The different forms of the (gustatory and nongustatory) $\mathrm{mmm}$ also allow it a certain flexibility. For example, it can be used to offer an evaluation, express uncertainty or doubt, or to show agreement with others. The $\mathrm{mmm}$ plus-evaluation sequence in the context of eating may work to reduce the ambiguity and allow it to be used for more particular purposes. It is therefore a general expression - not confined to any one situation - yet its meaning is constructed by situational and organizational features. It is worth noting here that both the vagueness and generality of the gustatory $\mathrm{mmm}$ afford it rhetorical strength, as with idiomatic expressions (Drew \& Holt, 1988; Edwards, 2000; Pomerantz, 1986). By not specifying exactly what is meant, the $\mathrm{mmm}$ is fairly robust in that it is resistant to refutation by other speakers (cf. Kitzinger, 2000). This links to the notion of systematic vagueness, through which factuality is alluded to, but never exactly specified (Edwards \& Potter, 1992; Potter, 1996; Wooffitt, 1992). A possible reason for this could be to avoid the necessity for further elaboration. If the $\mathrm{mmm}$ is not something that can be articulated in any other way, then the speaker cannot be held accountable for not providing further elaboration.

\section{Embodying the Experience}

The concern in this final section is to examine how the pleasure of eating is constructed as being primarily an embodied experience; that is, the gustatory $\mathrm{mmm}$ as a freestanding expression constructs pleasure as something that cannot readily be articulated in words. We have already 
seen elements of this in the discussions on immediacy, spontaneity, and vagueness, which alluded to the body as being prior to thought or language. This is an important, although apparently obvious, point. To appreciate this, we need to be aware of the distinction that separates the body from discourse, as discussed previously (see also Harré, 1999). This division sets up one side (the body) as being somehow more "real" or more fundamental than the other. For example, we may talk about what a food tastes like, but it is the physicality of taste that is treated as the more accurate source.

To show how embodiment is bound up with discursive features, we need to look at some examples in which the gustatory $\mathrm{mmm}$ is used as a freestanding expression. One way in which this might occur is instances in which the expression is used to provide agreement with, or confirmation of, another speaker's account. The ability of the $\mathrm{mmm}$ expression to display agreement has already been examined (Gardner, 1997; Koole, 1998; Schegloff, 1982), but the reference to taste or pleasure in some sense extends this. It give the agreement a basis - an account of the grounds on which the expression is made. In Extract 13, Ian displays such an affiliation with Sandra.

(13) SKW/K2a-M4 (77-83)

\begin{tabular}{|c|c|}
\hline & $(6.0)$ \\
\hline Sandra: & $\begin{array}{l}>^{\circ} \mathrm{ooh}^{\circ} \text { this has got }<\text { loads: on it (.) } \uparrow \text { hasn't it } \\
(0.6)\end{array}$ \\
\hline Ian: & $\underline{\mathrm{mmm}} \uparrow$ \\
\hline & $(1.2)$ \\
\hline Sandra: & $\begin{array}{l}{ }^{\circ}>\mathrm{mm}<{ }^{\circ}(0.2) \text { I like } \downarrow \text { Morrison's: pizza's: } \\
(1.0)\end{array}$ \\
\hline
\end{tabular}

Sandra's turn is already designed to seek a response through the addition of the tag question "hasn't it" (line 2; Schiffrin, 1987). The fact that Ian's $\mathrm{mmm}$ (line 4) includes some emphasis and rising intonation shows that additional work is going on here. It provides an agreement with Sandra, but adds an evaluative and bodily referent. The "loads on it" (line 2 ) is constructed retrospectively through Ian's expression of gustatory pleasure as being a positive, or pleasurable, state of affairs. There is no expressed need for elaboration; the $\mathrm{mmm}$ alone is treated as sufficient. Also note how Ian's $\mathrm{mmm}$ differs from the $\mathrm{mm}$ on line 6, which is speeded up and soft- 
ened. In the latter case, the $m m$ provides agreement (Gardner, 1997) but without the display of pleasure.

Extract 14 demonstrates how the act of eating food provides credibility for one's accounts of the food, as well as evidencing them. The body is viewed as the baseline against which food accounts are to be checkedthe physical is given credence over the verbal-mental. In this section of the interaction, the speakers are eating Christmas cake at the end of their meal.

(14) SKW/D2a-M3 (1087-1097)

1 Simon: its actually got $\downarrow$ quite a bit of: uhm

$2 \quad(0.6)>$ is it $<(0.2) \uparrow$ brandy or-

3 Anna: $\quad \uparrow \mathrm{mmm}$

4 Simon: $\quad$ rum $>$ or something<

$5 \quad(2.0)$

6 Jenny: $\rightarrow$ 个mm $[\mathrm{mm}$

7 Simon: $\rightarrow \quad \mathrm{L}_{\mathrm{mmm}}$

8 Jenny: $\quad>$ see what you mean $<$

9 Simon: $\quad$ by jove that- $^{\circ}$

10 Anna: $\quad \mathrm{L}_{\text {was on }}$ the box $\uparrow$ there's- $(0.4)$ there's a

11 few: different ingredients: in $\downarrow$ it (0.6) alcoholic

Simon's comment about the food "actually" having alcohol in it suggests that he has already tasted the pudding (lines 1-2). The "actually" here marks a contrast or revision to prior turns (Clift, 2001; Potter, 1996). However, it is not until another speaker, Jenny, expresses some pleasure in the food and refers back to Simon's account (line 8), that discussion of the alcohol content proceeds. The displays of gustatory pleasure in lines 6 and 7 therefore work to authenticate the claim of tasting alcohol and locate it in a framework of bodily sensations. This is something that is seemingly being experienced there and then by both Jenny and Simon, providing embodied proof that indeed, there is "quite a bit of" alcohol in the food. The "see what you mean" (line 8) then links the pleasure to the alcohol content in particular.

The embodiment of food pleasure is thus partly achieved through the use of the gustatory $\mathrm{mmm}$. By expressing an emphasized or exaggerated form of the term, the speaker references bodily sensations associated with pleasure - in this case, those derived from food. Note that other pleasures - for example, sexual experiences - may be similarly referenced in a 
different context (see Gardner, 2001, for a brief discussion of this). In the context of a mealtime, however, eating is one of the primary sources of reference. The gustatory $\mathrm{mmm}$ is one way in which to locate the talk in the physical or psychological aspects of this activity.

\section{CONCLUSIONS}

This article has argued that gustatory pleasure is sequentially organized in conversation and is oriented to other speaker turns; that is, pleasure is constructed within, and for, interaction. As a result, it is embedded within activities such as making a compliment, displaying alignment, or agreeing with another speaker. It can therefore be regarded as inseparable from conversational and eating practices, rather than as an internal, individual experience. It is also bound up with the practical management of food. Whether one expresses pleasure from eating may have consequences for how families negotiate the content of future meals, for example. This article therefore contributes to food research by reconceptualizing eating as an interactional and socially constructed activity (see also Wiggins et al., 2001). The construction of gustatory pleasure as an embodied, and individual, reaction to food also demonstrates the advantages of combining DP and CA approaches. Usually confined to the realms of social psychology, eating can be reconsidered as a situational and sequentially organized activity. It blurs the boundary between individual and interactional, in detailed and examinable ways.

The predominant $\mathrm{mmm}$-plus-evaluation pattern is shown in the analysis to construct pleasure as an immediate, spontaneous, and yet descriptively vague sensation. This affords it an authenticity, as an evaluation seemingly based on embodied sensations. The body is oriented to as being fundamental to taste and pleasure, but this must be seen as a construction, and as a topic for analysis in itself (Edwards, 1997; Edwards \& Potter, 1992). The notion of the gustatory $\mathrm{mmm}$ acting as a sensation receipt highlights this process of metaphorically separating the body from discoursethe private-public distinction - in other words, distinguishing pleasurable sensations from their public expression in discourse. By making this distinction both visible and problematic as a theoretical claim, the argument that DP cannot address issues of embodiment is itself problematized. The 
argument only holds if we treat embodiment and discourse as two separate, and bounded, domains.

This article also contributes to CA work on $m m m s$ and response tokens by detailing the predominant intonational and sequential pattern of the gustatory $\mathrm{mmm}$. This is characterized by an exaggerated and extended expression, located immediately before, during, or following the presence of food or eating. The gustatory $\mathrm{mmm}$ also typically features a rising or falling intonation. In this instance, a rising intonation is more likely to display a sensation receipt, as being an immediate reaction to the food. The expression is also associated with a topic shift to that of food or eating, with the $\mathrm{mmm}$ itself acting as an announcement of this shift (Extract 12 is a particularly good example of this). Therefore this article also builds on the notion of a news receipt (e.g., Heritage, 1984), with the gustatory $\mathrm{mmm}$ acting as a conversational resource and an analyzable construction of pleasure.

\section{NOTES}

1 Transcription symbols that deviate from the default Jeffersonian system are as follows:

$\uparrow$ Rising intonation

$\downarrow$ Falling intonation

2 Gardner (2001) also noted that mmms almost always occur at the start of a turn. Occasions in which they occur later in the turn are examined later toward the end of the article presented here, with a consideration of how this constructs both the "pleasure" and the talk itself.

3 I refer here to customs within British culture, on appropriateness and politeness during meals. Within this culture, it is generally considered bad manners, or rudeness, to talk with your mouth full. Apart from the disgust of being sprayed with spittle and pieces of chewed food, it is often hard to make out what the person is saying anyway.

4 One could examine the potential for gustatory $m m m s$ to serve as food acceptance receipts, although there is not space to tackle this in this article.

\section{REFERENCES}

Atkinson, J. M., \& Heritage, J. (Eds.). (1984). Structures of social action: Studies in conversation analysis. Cambridge, England: Cambridge University Press. 
Beardsworth, A., \& Keil, T. (1997). Sociology on the menu: An invitation to the study of food and society. London: Routledge.

Billig, M. (1999). Freudian repression: Conversation creating the unconscious. Cambridge, England: Cambridge University Press.

Bordo, S. (1997). Anorexia nervosa: Psychopathology as the crystallization of culture. In M. M. Gergen \& S. N. Davis (Eds.), Towards a new psychology of gender (pp. 423-453). London: Routledge.

Burkitt, I. (1999). Bodies of thought: Embodiment, identity and modernity. London: Sage.

Burningham, K. (1995). Attitudes, accounts and impact assessments. Sociological Review, $43,100-122$

Burr, V. (1995). An introduction to social constructionism. London: Routledge.

Burr, V. (1999). The extra-discursive in social constructionism. In D. Nightingale \& J. Cromby (Eds.), Social constructionist psychology: A critical analysis of theory and practice (pp. 113-126). Buckingham, England: Open University Press.

Cardello, A. V., Schutz, H., Snow, C., \& Lesher, L. (2000). Predictors of food acceptance, consumption and satisfaction in specific eating situations. Food Quality and Preference, 11, 201-216.

Clift, R. (2001). Grammar in interaction: The case of "actually." Unpublished manuscript, University of Essex, Essex, England.

Conner, M., Martin, E., Silverdale, N., \& Grogan, S. (1996). Dieting in adolescence: An application of the theory of planned behavior. British Journal of Health Psychology, $1,315-325$.

Conner, M., Povey, R., Sparks, P., James, R., \& Shepherd, R. (1998). Understanding dietary choice and dietary change: Contributions from social psychology. In A. Murcott (Ed.), 'The nation's diet': The social science of food choice (pp. 43-56). London: Longman.

Crossley, N. (2001). The social body. London: Sage.

Czyzewski, M. (1995). "Mm hm" tokens as interactional devices in the psychotherapeutic in-take interview. In P. Ten Have \& G. Psathas (Eds.), Situated order: Studies in the social organization of talk and embodied activities (pp. 73-89). Washington, DC: University Press of America.

DeVault, M. L. (1991). Feeding the family: The social organization of caring as gendered work. Chicago: University of Chicago Press.

Drew, P., \& Holt, E. (1988). Complainable matters: The use of idiomatic expressions in making complaints. Social Problems, 35, 398-417.

Dubé, L., \& Cantin, I. (2000). Promoting health or promoting pleasure? A contingency approach to the effect of informational and emotional appeals on food liking and consumption. Appetite, 35, 251-262.

Eagly, A. H., \& Chaiken, S. (1993). The psychology of attitudes. New York: Harcourt Brace Jovanovich.

Eagly, A. H., \& Chaiken, S. (1998). Attitude structure and function. In D. T. Gilbert, S. T. Fiske, \& G. Lindzey (Eds.), The handbook of social psychology (Vol. 1, 4th ed., pp. 269-322). New York: McGraw-Hill. 
Edwards, D. (1997). Discourse and cognition. London: Sage.

Edwards, D. (1999). Emotion discourse. Culture \& Psychology, 5, 271-291.

Edwards, D. (2000). The logic of extreme case formulations: Softeners, investment and irony. Research on Language and Social Interaction, 23, 347-373.

Edwards, D., \& Potter, J. (1992). Discursive psychology. London: Sage.

Frijters, J. E. R. (1987). Sensory sweetness perception, its pleasantness, and attitudes towards sweet foods. In J. Dobbing (Ed.), Sweetness (pp. 67-80). London: SpringerVerlag.

Gardner, R. (1997). The conversation object mm: A weak and variable acknowledging token. Research on Language and Social Interaction, 30, 131-156.

Gardner, R. (2001). When listeners talk: Response tokens and recipient stance. Amsterdam: Benjamins.

Geiselman, P. J., Smith, C. F., Williamson, D. A., Champagne, C. M., Bray, G. A., \& Ryan, D. H. (1998). Perception of sweetness intensity determines women's hedonic and other perceptual responsiveness to chocolate food. Appetite, 31, 37-48.

Gergen, K. (1999). An invitation to social construction. London: Sage.

Germov, J., \& Williams, L. (1996). The epidemic of dieting women: The need for a sociological approach to food and nutrition. Appetite, 27, 97-108.

Grogan, S. C., Bell, R., \& Conner, M. (1997). Eating sweet snacks: Gender differences in attitudes and behavior. Appetite, 28, 19-31.

Harré, R. (1999). Discourse and the embodied person. In D. J. Nightingale \& J. Cromby (Eds.), Social constructionist psychology: A critical analysis of theory and practice (pp. 97-112). Buckingham, England: Open University Press.

Heritage, J. (1984). A change of state token and aspects of its sequential placement. In J. M. Atkinson \& J. Heritage (Eds.), Structures of social action: Studies in conversation analysis (pp. 299-345). Cambridge, England: Cambridge University Press.

Herman, C. P., \& Polivy, J. (1980). Restrained eating. In A. J. Stunkard (Ed.), Obesity (pp. 208-225). Philadelphia: Saunders.

Hetherington, M. M., Pirie, L. M., \& Nabb, S. (1998). Pleasure and monotony: Effects of repeat exposure on pleasantness, desire to eat and intake. Appetite(Abstracts), 31, 251.

Hill, A. J., \& Franklin, J. A. (1998). Mothers, daughters and dieting: Investigating the transmission of weight control. British Journal of Clinical Psychology, 37, 3-13.

Hutchby, I., \& Wooffitt, R. (1998). Conversation analysis: Principles, practices and applications. Cambridge, England: Polity Press.

Jefferson, G. (1984). Notes on a systematic deployment of the acknowledgement tokens "yeah" and "mm hm." Papers in Linguistics, 17, 197-217.

Jefferson, G. (1985). An exercise in the transcription and analysis of laughter. In T. A. van Dijk (Ed.), Handbook of discourse analysis: Vol. 3. Discourse and dialogue (pp. 25-34). London: Academic.

Jefferson, G., Sacks, H., \& Schegloff, E. A. (1987). Notes on laughter in the pursuit of intimacy. In G. Button \& J. R. E. Lee (Eds.), Talk and social organization (pp. 152-205). Clevedon, England: Multilingual Matters. 
Kempen, H. J. G. (1998). Mind as body moving in space: Bringing the body back into selfpsychology. In H. J. Stam (Ed.), The body and psychology (pp. 54-70). London: Sage.

Kitzinger, C. (2000). How to resist an idiom. Research on Language and Social Interaction, 33, 121-154.

Koole, T. (1998). Affiliation and detachment in interviewer answer receipts. In H. van den Berg, H. Houtkoop-Steenstra, \& M. Wetherell (Eds.), Analyzing racist discourse: Multidisciplinary approaches. Cambridge, England: Cambridge University Press.

Lupton, D. (1996). Food, the body and the self. London: Sage.

Mead, M. (1997). The changing significance of food. In C. Counihan \& P. Van Esterik (Eds.), Food and culture: A reader (pp. 11-19). London: Routledge.

Meigs, A. (1997). Food as a cultural construction. In C. Counihan \& P. Van Esterik (Eds.), Food and culture: A reader (pp. 95-106). London: Routledge.

Mulkay, M. (1988). On humour: Its nature and its place in modern society. Cambridge, England: Polity Press.

Nofsinger, R. E. (1991). Everyday conversation. London: Sage.

Ochs, E., Pontecorvo, C., \& Fasulo, A. (1996). Socializing taste. Ethnos, 61, 7-46.

Parker, I. (Ed.). (1998). Social constructionism, discourse and realism. London: Sage.

Pomerantz, A. (1986). Extreme case formulations: A way of legitimizing claims. Human Studies, 9, 219-229.

Pontecorvo, C., \& Fasulo, A. (1999). Planning a typical Italian meal: A family reflection on culture. Culture \& Psychology, 5, 313-336.

Potter, J. (1996). Representing reality. London: Sage.

Potter, J. (1997). Discourse analysis as a way of analyzing naturally occurring talk. In D. Silverman (Ed.), Qualitative research: Theory, method and practice (pp. 144-160). London: Sage.

Potter, J. (1998). Discursive social psychology: From attitudes to evaluative practices. European Review of Social Psychology, 9, 233-266.

Potter, J., \& Wetherell, M. (1987). Discourse and social psychology: Beyond attitudes and behavior. London: Sage.

Puchta, C., \& Potter, J. (1999). Asking elaborate questions: Focus groups and the management of spontaneity. Journal of Sociolinguistics, 3, 314-335.

Sacks, H. (1992). Lectures on conversation (Vols. 1-2). Oxford, England: Blackwell.

Sacks, H., Schegloff, E. A., \& Jefferson, G. (1974). A simplest systematics for the organization of turn-taking in conversation. Language, 50, 696-735.

Sampson, E. E. (1998). Establishing embodiment in psychology. In H. J. Stam (Ed.), The body in psychology (pp. 30-53). London: Sage.

Schegloff, E. A. (1982). Discourse as an interactional achievement: Some uses of 'uh huh' and other things that come between sentences. In D. Tannen (Ed.), Analyzing discourse: Text and talk (pp. 71-93). Washington, DC: Georgetown University Press.

Schiffrin, D. (1987). Discourse markers. Cambridge, England: Cambridge University Press. 
Verkuyten, M. (1998). Attitudes in public discourse: Speakers' own orientations. Journal of Language and Social Psychology, 17, 302-322.

Visser, M. (1986). Much depends on dinner. Toronto: McClelland \& Stewart.

Visser, M. (1991). The rituals of dinner: The origins, evolution, eccentricities, and meaning of table manners. Harmondsworth, England: Penguin.

Wardle, J. (1988). Cognitive control of eating. Journal of Psychosomatic Research, 32, $607-612$.

Wiggins, S. (2001). Construction and action in food evaluation: Conversational data. Journal of Language and Social Psychology, 20, 445-463.

Wiggins, S., Potter, J., \& Wildsmith, A. (2001). Eating your words: Discursive psychology and the reconstruction of eating practices. Journal of Health Psychology, 6, 5-17.

Willig, C. (2000). A discourse-dynamic approach to the study of subjectivity in health psychology. Theory \& Psychology, 10, 547-570.

Wittgenstein, L. (1953). Philosophical investigations. Oxford, England: Blackwell.

Wooffitt, R. (1992). Telling tales of the unexpected. Hemel Hempstead, England: Harvester Press. 